\title{
Participación política y sistema electoral
}

\author{
Walter Albán Peralta*
}

Desde la vigencia de la Constitución de 1979, los mecanismos de consulta de la voluntad popular y la cuestión electoral en general han experimentado en el Perú múltiples y significativos cambios. Es evidente, sin embargo, que tales cambios no fueron realizados en función de un diseño claramente concebido de lo que se quería hacer, y mucho menos han generado un sistema coherente de normas y organización estatal en materia electoral, orientado al fortalecimiento y desarrollo de la vida democrática en el país. Por el contrario, las más de las veces, hemos asistido a modificaciones o innovaciones en este campo, como respuesta a coyunturas políticamente delicadas y a contextos específicos, en los que se buscó salidas inmediatas o expeditivas a situaciones complejas, sin una clara visión de los impactos que pudieran producir tales decisiones o la consistencia de las mismas.

Han transcurrido ya casi tres décadas desde entonces y se hace necesario ahora, después de la importante experiencia acumulada, hacer un balance del proceso seguido hasta el momento, con el ánimo de contribuir a un debate que resulta indispensable para llevar a cabo una revisión de varios de los temas sustantivos en el ámbito electoral. Bajo las actuales circunstancias, tales temas pueden resultar determinantes en el objetivo de consolidar la democracia, dotándola de instrumentos e instituciones funcionales a una realidad tan compleja como la peruana.

La revisión propuesta constituye además una tarea necesaria en el propósito de afirmar una positiva tendencia que ha prevalecido en las últimas décadas, independientemente del carácter coyuntural y en algunos casos inconveniente con el que han tenido lugar muchas de las modificaciones o innovaciones

Profesor principal de la Facultad de Derecho de la PUCP y miembro del Instituto de Derechos Humanos de la misma universidad (IDEHPUC), donde también integra la plana docente de la maestría en Derechos Humanos. 
legislativas vinculadas a la participación política ciudadana. En efecto, el derecho de sufragio, por ejemplo, tradicionalmente retaceado y restringido a sectores determinados de la población, fue progresivamente ampliado en sus alcances hasta posibilitar, recién a partir de la Constitución de 1979, como lo señala Tuesta Soldevilla, «[...] elecciones realmente competitivas [...], libres e inclusivas». ${ }^{1}$

Este mismo autor afirma que antes de 1980, los procesos electorales se encontraban seriamente cuestionados, anulados o con candidato único, lo que contrasta con lo ocurrido entre 1980 y 1995. «En este período la población casi se duplica, los candidatos y los partidos políticos exigen un mayor control e imparcialidad, los ciudadanos transparencia y entrega de resultados de manera rápida y los procesos electorales se incrementan en número». ${ }^{2}$

Se trata, por lo tanto, de realizar ahora un serio intento por dotar a nuestros procesos electorales, y al sistema político en general, de un diseño consistente, funcional y, lo que es más importante, acorde con los derechos humanos y los derechos fundamentales consagrados en la Constitución y en los instrumentos internacionales de los que el Perú forma parte.

En ese marco, interesa por cierto evaluar algunas opciones cuya pertinencia debe ser examinada a la luz de diferentes consideraciones, tales como los antecedentes disponibles y la experiencia comparada, así como valores o elementos subjetivos presentes en una sociedad como la peruana, constitucionalmente reconocida como pluriétnica y pluricultural.

De otro lado, no obstante la clara intención con la que el denominado Congreso Constituyente Democrático (CCD) elaboró la Constitución vigente, dado el propósito reeleccionista que animaba a la mayoría de sus miembros, es también evidente que — precisamente, en el ánimo de asegurar ese objetivo- se introdujeron algunas figuras novedosas que, en sí mismas, cabría admitir como instrumentos capaces de mejorar el funcionamiento de nuestra frágil democracia. En ese contexto aparecieron, por ejemplo, los llamados mecanismos de democracia directa, tales como el referéndum o la revocatoria, e instituciones como la Defensoría del Pueblo, esta última con características muy similares al Defensor del Pueblo de España, establecido conforme a su Constitución de 1978 con un mandato centrado en la defensa y protección de los derechos humanos.

Esta misma perspectiva ha sido asumida en años recientes cuando, recuperada la vida democrática en el país, el debate político desarrollado en torno a la conveniencia de promover una reforma constitucional que pocos ponen en duda, aun en sus versiones más radicales —el retorno inmediato a la vigencia

Tuesta SoldeVILla, Fernando. «La organización electoral en el Perú», p. 1. Documento presentado en el seminario Junta Central Electoral: Alternativas para una Elección de Consenso. lbíd. 
de la Constitución de 1979-, ha hecho énfasis en señalar que ello en modo alguno podría suponer la desaparición de los mecanismos de participación que no estuvieron previstos en aquella Constitución, al igual que una entidad tan importante como la Defensoría del Pueblo.

Pero ¿qué decir de los demás cambios producidos desde la década pasada? Y ¿qué otros aspectos cabría contemplar en un rediseño que pretenda sistematizar y dar consistencia a una normatividad que, como ha quedado señalado, pretenda aportar al desarrollo democrático del país?

En esa dirección, el presente trabajo intenta contribuir a la revisión planteada, partiendo al efecto de un rápido recuento del proceso seguido a partir de 1992, cuando la interrupción del régimen constitucional abrió paso a un conjunto de cambios importantes en diferentes ámbitos, expresados en la sustitución de la Carta de 1979 por la aún vigente de 1993.

Complementariamente, se pretende una reflexión más detenida sobre tres de los temas que han estado presentes en el debate político nacional, a propósito de las modificaciones a la actual legislación electoral o a la propia Constitución. Tales temas son: la representación política en el Congreso, las instituciones electorales y los partidos políticos.

\section{El diseño de la Carta de 1979}

En pocas oportunidades en su historia, el Perú ha contado con un texto constitucional surgido de una profunda reflexión y un amplio debate, en el que tuvieron opción de participar todos los grupos políticos en ese momento relevantes en la escena nacional. ${ }^{3}$ Paralelamente, no cabe duda que los once años de gobierno militar habían dado lugar a la ejecución de un conjunto de políticas de Estado que modificaron sustantivamente, no solo la composición del mismo y su organización, sino diferentes e importantes aspectos de la realidad del país.

Los constituyentes de ese entonces tuvieron, en consecuencia, muy presente la necesidad de entregarle a las peruanas y peruanos una Constitución que incorporara aquello que nuestra historia republicana permitiera calificar como aconsejable, enriqueciendo esta perspectiva con aportes tomados directamente del desarrollo constitucional de las democracias más avanzadas en ese momento. Pero, al mismo tiempo, había que tratar de expresar y responder a la realidad

La elección de los representantes al Congreso Constituyente en 1978, no obstante haber sido convocada por el gobierno militar presidido en ese entonces por el general Francisco Morales Bermúdez, no fue objeto de críticas o denuncias que pudieran haber empañado sus resultados. Por el contrario, existe un amplio consenso respecto a la limpieza con la que se desarrolló aquella elección y la apertura para permitir la participación de organizaciones representativas de toda la gama de opciones políticas o ideológicas. En ese sentido, la decisión de Acción Popular de no tomar parte en la Constituyente, no puede entenderse como una ausencia capaz de dejar sin voz en ese Congreso, a sectores significativos de la sociedad. 
de un país que en esos once años había experimentado profundos cambios, dando sobradas muestras de su complejidad y tremendo potencial, así como de los riesgos que tendría que afrontar cualquier proyecto democrático que se propusiera desarrollar en él.

Quizá fue a eso a lo que se refería Víctor Raúl Haya de la Torre, cuando en su discurso de instalación de la Asamblea, al asumir la presidencia de la misma, señaló expresamente que la Constitución que habrían de brindar al país sería una cuyos contenidos no solamente reflejaran la democracia que se quería reestablecer a partir de 1980, sino aquella con la que nos preparábamos para iniciar el nuevo siglo. Dijo entonces Haya de la Torre sobre la Constitución cuya elaboración les había sido encomendada:

Debe estar guiada, además, por un sentido y una proyección de futuro. No legislamos para hoy ni para el inmediato mañana. La Constitución, si tenemos la sabiduría de concebirla realistamente, apropiadamente, debe tener vigencia para varias generaciones. Ha de ser lo bastante previsora y flexible para renovarse y renovar, confirmándose como un marco que permita el desarrollo de la sociedad peruana, lo promueva y lo encauce. Y si la defectuosa Constitución de 1933 — por su obsoleto estilo y espíritu — es la última Constitución del siglo veinte, la que se dicte ahora deberá ser la primera Constitución del Siglo XXI. Una Carta Política que, por su participación, modernidad y alcance resulte válida para ese siglo futuro - que muchos no habremos de ver- pero cuyos resplandores aurorales empiezan a dejarse sentir en nuestros conturbados tiempos. ${ }^{4}$

Fue en ese contexto y con tales antecedentes, que los constituyentes de 1979 optaron por establecer en el Perú un diseño que entró a regir desde las elecciones de 1980 y que consagró, entre otros aspectos principales, los siguientes:

- Un Congreso bicameral compuesto por 240 miembros - 180 diputados y 60 senadores elegidos los primeros por distrito múltiple y los segundos por distrito único-. ${ }^{5}$

- Un órgano electoral único, el Jurado Nacional de Elecciones, a cargo de todos los procesos electorales, dependiendo de él tanto el registro electoral como el registro de partidos políticos.

- Los partidos políticos como instrumento fundamental para la participación política ciudadana, así como el derecho de todo ciudadano a asociarse en partidos políticos y a participar democráticamente en ellos (artículo 68).

http://apracerll.pe.tripod.com/Discurso.htm

5 El artículo 165 de la Constitución de 1979 contemplaba que tratándose de la elección de senadores, esta se realizaría por regiones, pero la cuarta disposición transitoria de esa Carta señaló que en tanto tales regiones no estuvieran constituidas, el Senado sería elegido en distrito nacional único. 


\section{Los cambios en la Constitución de 1993 y las modificaciones posteriores}

Los tres temas anteriormente señalados, fueron materia de modificaciones sustantivas que han incidido desde entonces en forma determinante en la vida política en el país. Nuevas coyunturas, sin embargo, particularmente la que correspondió al cuestionamiento del proceso electoral del año 2000, seguido de la instalación de una Mesa de Diálogo promovida por la Organización de Estados Americanos (OEA) hacia septiembre de ese mismo año, así como debates más recientes en el Congreso de la República, han dado lugar a otras importantes modificaciones o cuando menos puesto en evidencia la voluntad de producirlas en estos mismos aspectos.

En tal sentido, se exponen a continuación algunos de los aspectos de mayor interés comprendidos en las modificaciones ya verificadas o propuestas, así como los argumentos relevantes que cabría destacar, sea para coincidir o para discrepar respecto de las opciones en juego en cada uno de los temas.

\subsection{La representación en el Congreso}

En septiembre de 2001, la Defensoría del Pueblo publicó, a partir de la supervisión realizada al proceso electoral de ese año, un conjunto de recomendaciones para una reforma electoral. Entre ellas se consideró, en primer lugar, la conveniencia de mejorar la representatividad política en el Congreso de la República, aumentando el número de sus miembros. En este sentido, recordaba esta publicación que ya en las elecciones de 1919 se había elegido a un total de 138 representantes; 141 en 1929; 189 en 1945; 196 en 1950; 237 en 1956; 185 en 1963, hasta llegar en las elecciones de 1980, 1985 y 1990 a un total de 240 representantes. ${ }^{6}$ Un dato complementario nos lo proporciona Jorge Basadre, al registrar que ya en 1912, el Perú tenía una población votante de 143,766 electores y estos elegían a un total de 162 congresistas. ${ }^{7}$

No cabe duda que un Congreso unicameral como el actual, de 120 miembros, restringe drásticamente las posibilidades de una representación política acorde con la realidad del país bajo las actuales circunstancias. En efecto, considerando la secuencia anterior, tenemos que para una población estimada en no más de cinco millones en 1912, el Congreso contaba con un mayor número de

\footnotetext{
Defensoría del Pueblo. Hacia una reforma del sistema electoral. Lima: septiembre 2001, pp. 7 y 8.

7 BASADRE, Jorge. Historia de la República del Perú 1822-1933. Primera edición. Orbis Ventures S.A.C., 2005.
} 
representantes de los que hoy día se pretende representen a más de 27 millones de peruanas y peruanos. ${ }^{8}$

Comparativamente en la región andina, como lo anota Fernando Tuesta, el Perú resulta ser el segundo país con mayor población, pero el último si consideramos el número de representantes. A nivel latinoamericano, entre diecinueve países el Perú ocupa el puesto quince en relación con el total de parlamentarios, no obstante ser el quinto país con mayor población. Los cuadros 1 y 2, elaborados por el mismo autor, dan cuenta detallada de estos alcances en la Comunidad Andina. ${ }^{9}$

Cuadro 1. Características de los parlamentos andinos

\begin{tabular}{|lcccccc|}
\hline País & Senado & $\begin{array}{c}\text { Cámara } \\
\text { Baja }\end{array}$ & $\begin{array}{c}\text { Cámara } \\
\text { única }\end{array}$ & Total & Período & Reelección \\
\hline Colombia & 102 & (Representantes) 161 & & 263 & 4 años & Indefinida \\
Venezuela & 57 & (Diputados) 189 & & 246 & 5 años & Indefinida \\
Bolivia & 27 & (Diputados) 130 & & 157 & 5 años & Indefinida \\
Ecuador & & & 121 & 121 & 4 años & Indefinida \\
Perú & & & 120 & 120 & 5 años & Indefinida \\
Total & $\mathbf{1 8 6}$ & $\mathbf{4 8 0}$ & $\mathbf{2 4 1}$ & $\mathbf{9 0 7}$ & & \\
\hline
\end{tabular}

Cuadro 2. Número de habitantes / electores por parlamentario

\begin{tabular}{|lcccc|}
\hline País & $\begin{array}{c}\text { Población } \\
1998 \text { (miles) }\end{array}$ & $\begin{array}{c}\text { Electores } \\
\mathbf{1 9 9 8}\end{array}$ & $\begin{array}{c}\text { Número de habitantes } \\
\text { por parlamentario } \\
1998\end{array}$ & $\begin{array}{c}\text { Número de electores } \\
\text { por parlamentario } \\
1998\end{array}$ \\
\hline Perú & 24.801 & 13.361 .355 & 206.675 & 111.345 \\
Colombia & 37.683 & 20.729 .473 & 143.281 & 78.819 \\
Ecuador & 12.175 & 7.072 .496 & 100.619 & 58.45 \\
Venezuela & 23.242 & 10.991 .482 & 94.48 & 44.68 \\
Bolivia & 7.957 & 3.252 .791 & 50.681 & 20.718 \\
Comunidad & & & & 62.802 \\
Andina & 105.858 & 55.407 .597 & 119.147 & \\
\hline
\end{tabular}

8 No es posible hacer una comparación referida específicamente a la población electoral, toda vez que la participación política se encontraba antes de 1963 limitada y no tenía por ende carácter universal.

9 TUeStA Soldevilla, Fernando. Fujimori, la oposición y las reglas. Lima: Fundación Friedrich Eber, 1999. 
Esta constatación motivó que la Defensoría del Pueblo ya en aquella oportunidad planteara la conveniencia de ir a una reforma constitucional, en la que pudiera considerarse la vuelta a un Congreso bicameral. De esa manera, se sugería una Cámara de Diputados elegida sobre la base de circunscripciones departamentales — distrito electoral múltiple- y un Senado elegido por distrito electoral único. En cualquier caso, concluía la Defensoría del Pueblo, aun manteniéndose el sistema unicameral, resultaba necesario insistir en la conveniencia de ampliar el número de representantes al Congreso, a fin de alcanzar un número que guardara proporción con la actual población electoral en el país.

Ahora bien, una evaluación detenida sobre la experiencia de la unicameralidad en el Perú, conduce a reafirmar la conveniencia de reestablecer la bicameralidad, cualquiera sea la vía que finalmente se adopte para una reforma constitucional que está pendiente desde años atrás, luego de la recuperación de la democracia al caer el régimen autoritario de Fujimori en noviembre del año 2000.

En efecto, más allá del efectista argumento de una supuesta reducción del gasto esgrimido en el CCD para establecer la unicameralidad, es evidente que lo que sí se redujo fue la representación política en el Congreso, afectando seriamente la relación del mismo con la ciudadanía. Así, no solamente se recortó la posibilidad de que la población tuviera un número de representantes acorde con la evolución demográfica en el país, sino que además se estableció un mecanismo de elección por distrito nacional único, con lo que los electores perdían toda vinculación efectiva con esos pocos representantes elegidos.

En cuanto a lo primero, los datos que consigna César Delgado-Guembes respecto al presupuesto proyectado del Congreso bicameral en 1992, indican que el monto de los recursos asignados al mismo ascendía a un total de 123 millones, 436 mil nuevos soles. ${ }^{10} \mathrm{El}$ cuadro 3 permite apreciar de qué manera los sucesivos presupuestos del actual Congreso unicameral superaron con creces ese monto.

10 Delgado-Guembes, César. ¿Qué Parlamento queremos? Lima: Editorial Cusco, 1992, p. 528. 


\section{Cuadro 3. Presupuesto del Congreso Nacional}

\begin{tabular}{|lc|}
\hline Años & Millones de nuevos soles \\
\hline 1998 & 180.00 \\
1999 & 212.00 \\
2000 & 244.00 \\
2001 & 251.00 \\
2002 & 268.00 \\
2003 & 280.90 \\
2004 & 283.00 \\
\hline
\end{tabular}

Fuente: página web del Instituto Nacional de Estadística e Informática (INEI)

El supuesto ahorro en consecuencia no fue tal, pero no cabe duda que un Congreso reducido y desvinculado en términos reales del control ciudadano, resultó muy funcional al régimen para el ejercicio autoritario del poder. El avasallamiento a la institucionalidad, que caracterizó al gobierno de esos años, no fue necesario en un Parlamento claramente controlado por la mayoría oficial, que se encargó de aprobar o legitimar todas las medidas que interesaban a quienes decidían desde palacio o - como se pudo constatar ampliamente después - desde las oficinas del Servicio de Inteligencia Nacional.

Más adelante, durante los meses previos a la caída del régimen, instalada la denominada Mesa de Diálogo (MD) convocada por la OEA y cuando Fujimori se vio forzado a convocar a nuevas elecciones generales para el 2001, luego del escándalo del vladivideo, los participantes se dedicaron a tratar las reformas que habría que emprender de inmediato a fin de que pudieran ser aplicadas en la nueva consulta electoral.

En tales circunstancias, la absoluta falta de legitimidad del Congreso, derivada del fuerte cuestionamiento a las elecciones del año 2000, a lo que se sumó el escándalo del transfuguismo, hizo que el eje del debate político en el país se trasladara a la MD, en la que tomaron parte representantes del oficialismo, de la oposición y de la sociedad civil, además de la propia Defensoría del Pueblo.

De esa manera, se adoptó un mecanismo sui géneris para la aprobación de las nuevas reglas electorales y en otros ámbitos, que supuso el compromiso de las diferentes organizaciones políticas para, en el Congreso de la República, aprobar de manera inmediata y sin debate previo, los acuerdos a los que se llegaba en la MD.

Tal estado de cosas constituyó un momento excepcional en el país en el que, por obvias razones, no se dieron las condiciones para una completa revisión de 
los diversos aspectos que merecían ser considerados para una reforma con el reestablecimiento de la democracia.

En ese sentido, en lo que tocaba al tema electoral, la MD únicamente se limitó a discutir si las elecciones del 2001 serían convocadas para un Congreso a elegir por distrito electoral único - como habían sido todas las elecciones desde que se instaló el Congreso unicameral — o se optaba por atender lo que se percibía nítidamente como una demanda popular, aprobando la fórmula del distrito electoral múltiple. Expresamente se optó en consecuencia por postergar la cuestión de una eventual vuelta a la bicameralidad, para un Congreso posterior, bajo circunstancias regulares.

Finalmente, no sin antes vencer algunas resistencias, ${ }^{11}$ se aprobó la fórmula del distrito múltiple con lo que, luego de casi once años, se pudo contar en el Congreso de la República con representantes de todos los departamentos del país.

El período de gobierno del presidente Alejandro Toledo, iniciado en julio de 2001, abrió entonces el espacio para la discusión sobre la bicameralidad en el Congreso, en el marco de un debate más amplio en torno a la reforma constitucional que, hasta ese momento, todos los grupos políticos allí representados anunciaron que habría de producirse en un plazo más bien corto. Como se conoce, esa reforma finalmente no se llegó a concretar sino en aspectos muy específicos, y la mayor parte de los temas — bicameralidad incluidahan quedado a consideración del nuevo Congreso instalado en julio del 2006.

A todos los argumentos que han sido ya expresados relacionados con nuestra historia republicana a favor de la bicameralidad, se suma la constatación de la gran cantidad de proyectos aprobados durante el Congreso pasado que fueron materia de observación presidencial. ${ }^{12}$ Ello, a la par de generar nocivas fricciones entre uno y otro poder del Estado cuando - como ocurrió durante la década pasada - el gobierno no cuenta con una mayoría obsecuente en el Congreso, constituye un indicio evidente de la necesidad de establecer una cámara revisora, que pueda hacer de filtro de las decisiones legislativas que, dada su trascendencia, debieran ser objeto del más amplio debate antes de su aprobación y puesta en vigencia.

11 El autor pudo participar en tales debates en representación de la Defensoría del Pueblo y, en este punto, el acuerdo para optar por el distrito múltiple fue posterior a varios intentos no siempre explícitos para mantener el distrito único. Al parecer, de no haberse percibido una fuerte presión externa hacia los partidos para llegar a esta fórmula de elección, tanto el oficialismo como la mayoría de la oposición habrían preferido ir a las elecciones generales del 2001 con el mecanismo del distrito único.

12 Entre el año 2001 y el 2006 se llegaron a observar por el Ejecutivo, un total de 348 autógrafas de ley. 
Ese mayor espacio para el debate, de un lado, contribuye de manera indirecta a una mejor información y formación de la opinión pública ciudadana, componente esencial de las democracias contemporáneas. De otro lado, constituye un elemento de protección contra decisiones apresuradas que, bajo las actuales condiciones, independientemente del juicio de valor que se pueda realizar sobre ellas, pueden resultar totalmente contraproducentes y terminar afectando aún más la ya débil legitimidad del Congreso.

Por último, en este mismo tema, no podemos dejar de considerar la importancia del proceso de descentralización iniciado en el país durante los años anteriores. En este sentido, no obstante las dificultades, deficiencias y retos por superar de este peculiar esfuerzo descentralista — que ha permitido instalar en el país desde octubre de 2003, veinticinco gobiernos regionales, cuando todavía no se han constituido verdaderas regiones-, todo conduce a tratar de superar tales problemas en aras de avanzar hacia una democracia inclusiva, capaz de incorporar una demanda largamente postergada y altamente sensible para una mayoría de la población del país, que es la que reside fuera de la ciudad capital.

Bajo tales consideraciones, resulta aconsejable que, en el contexto de las inevitables tensiones que ya se han generado, y que previsiblemente habrán de incrementarse, entre las autoridades locales y regionales y el gobierno central, la representación parlamentaria no quede compuesta exclusivamente por quienes han sido elegidos en función de circunscripciones electorales con base territorial departamental o provincial. Una Cámara más reducida, elegida por distrito electoral único o nacional, contribuiría decididamente a establecer un equilibrio entre el enfoque y la defensa del legítimo interés local, con una perspectiva de alcance nacional, promoviendo así la necesaria unidad en la diversidad.

\subsection{El sistema electoral: ¡un monstruo de tres cabezas?}

Uno de los puntos de mayor controversia desde que entró en vigencia la Constitución de 1993 ha sido, sin duda, la creación de tres organismos electorales con funciones diferenciadas. Así, el Jurado Nacional de Elecciones (JNE), la Oficina Nacional de Procesos Electorales (ONPE) y el Registro de Identificación y Estado Civil (RENIEC) constituyeron desde ese momento lo que la Constitución denomina un sistema electoral en el Perú. ${ }^{13}$

En el difícil contexto político por el que atravesaba el país, no fueron pocos los que afirmaron que esta división de funciones originada por la creación de tres entidades autónomas, no tenía otro propósito que el de hacer más frágil al órgano electoral, al diversificar atributos y competencias, posibilitando así un

13 Especialistas como Fernando Tuesta han criticado desde una perspectiva más técnica esta denominación de sistema, que según ellos debería reservarse a las modalidades de elección de las representaciones parlamentarias. 
manejo instrumental de las nuevas instituciones, a las que se pretendía comprometer con el objetivo de asegurar la reelección del presidente Fujimori para el año 1995.

Estos cuestionamientos de origen, fueron seguidos de fuertes críticas que, por diferentes razones, se formularon contra la actuación que en los años siguientes desarrollaron tanto el JNE, como la ONPE y el RENIEC. Más allá de los aspectos técnicos y administrativos comprendidos también en tales críticas, es importante destacar la manera en la que estos órganos fueron afectando progresivamente su imagen y credibilidad, conforme se hicieron más evidentes los afanes autoritarios y de avasallamiento de la institucionalidad que caracterizaron al gobierno de entonces, así como los fuertes cuestionamientos a la limpieza de los procesos de consulta llevados a cabo en los años 1993 y 1995, referidos al referéndum aprobatorio de la actual Constitución y las elecciones generales, respectivamente.

El creciente desprestigio de las instituciones electorales llegó sin embargo a su más alto nivel a propósito de las elecciones generales del año 2000, en las que resulto reelecto, por segunda vez, Alberto Fujimori. En efecto, dadas las particulares condiciones en las que tuvo lugar esta elección, las crecientes protestas al interior del país, así como la presión de la comunidad internacional, el gobierno se vio precisado a aceptar una Misión de Observación Electoral (MOE) de la OEA, presidida por el embajador de origen guatemalteco, don Eduardo Stein.

El trabajo de la MOE, articulado a organizaciones de la sociedad civil tales como la Coordinadora Nacional de Derechos Humanos y la Asociación Civil Transparencia, sumado al de otras entidades como el Centro Carter y la Defensoría del Pueblo, resultó de particular importancia para advertir las deficiencias en la actuación de los organismos electorales. Tales deficiencias e irregularidades fueron materia de un seguimiento cuidadoso por parte de la MOE y llevaron a su máximo vocero, el embajador Stein, a declarar aun en medio del proceso electoral, que se habían constatado deficiencias monumentales en la actuación cumplida en ese entonces por la ONPE.

Concluidas las elecciones que consagraban la nueva reelección, el informe de la MOE —que concluyó señalando que el proceso electoral realizado no había sido limpio ni transparente- resultó determinante para que la Asamblea General de la OEA celebrada en Windsor, Canadá, en junio del año 2000, expresara su preocupación por el proceso político peruano y se pronunciara a favor de enviar una misión especial al Perú, presidida por el entonces secretario general de la organización, César Gaviria, y de la que también formó parte el ex canciller de Canadá, Lloyd Axworthy.

El resultado más importante de la nueva Misión fue el establecimiento de la MD que, como quedara dicho, al momento de crear consenso para algunas 
reformas inmediatas en la legislación electoral, no incluyó — dada la dimensión de la tarea- la cuestión de los órganos electorales, a pesar de su absoluto descrédito para ese momento y de la indiscutible necesidad de revisar a fondo los cambios que sufrieron desde la Constitución de 1993.

No obstante haber sido diferida la discusión sobre el diseño de la organización electoral y sus instituciones, fue evidente la necesidad de contar en un corto plazo con nuevos titulares en esos organismos, resultando particularmente importante la designación del nuevo jefe de la ONPE. En este sentido, si bien era necesario que conforme a ley esta elección recayera en el Consejo Nacional de la Magistratura, era al mismo tiempo indispensable que quien resultara designado contara con la confianza de las diferentes organizaciones que en ese momento se aprestaban a competir en el nuevo proceso electoral convocado para abril de 2001.

En esas condiciones, Fernando Tuesta Soldevilla, un prestigioso especialista en temas electorales que había asesorado a la MD en estos asuntos durante los meses anteriores, apareció como la figura de mayor consenso entre los partidos y organizaciones políticas para asumir tan delicado encargo. De esta manera, en diciembre del año 2000, eligiendo entre una terna que le fue propuesta por el Congreso de la República, el Consejo Nacional de la Magistratura procedió a designar a Fernando Tuesta como nuevo jefe de la ONPE por los siguientes cuatro años.

El reto que tuvo Tuesta Soldevilla por delante no suponía entonces ocuparse solamente de recomponer los cuadros directivos, evaluar los recursos humanos y materiales de los que disponía la ONPE, y preparar un proceso electoral general que debía ser organizado bajo tan excepcionales circunstancias, en un plazo sumamente breve. ${ }^{14}$ Se trataba también, y de manera más importante, de recuperar —o más bien crear- la legitimidad ante la opinión pública para esa institución y los organismos electorales en general.

$\mathrm{Al}$ margen de las dificultades materiales, técnicas y hasta legales con las que tuvo que lidiar la organización del proceso electoral del año 2001, y teniendo por cierto presente la importante colaboración brindada por la comunidad internacional para asegurar el éxito del proceso, los resultados obtenidos por la «nueva» ONPE permitieron superar con creces tales retos.

En efecto, los resultados electorales de ese año, tanto en primera como en segunda vuelta, fueron aceptados por todos como producto de un proceso limpio y competitivo, donde las dificultades advertidas no alcanzaron una magnitud suficiente como para poder empañar la actuación de los organismos electorales.

4 Dado que las elecciones debían realizarse en abril del 2001, el plazo efectivo para su organización era de apenas 4 meses y 16 días. 
Inaugurada esta nueva etapa y recuperada la confianza en el sistema electoral, el tema de la organización del mismo fue incluido, como era previsible, en el debate abierto a propósito de la reforma constitucional. Y en ese sentido, uno de los puntos principales a dilucidar tenía y tiene que ver con la conveniencia de apartarse del esquema consagrado por la Constitución de 1993 y volver a un solo órgano que de manera exclusiva pudiera asumir todas las funciones y competencias de orden administrativo, jurisdiccional y de registro.

En los últimos años, ha sido constante el reclamo de los miembros del JNE para volver al diseño anterior y recurrente su planteamiento de que no conviene mantener vigente lo que han denominado el monstruo de las tres cabezas. Dicho planteamiento atrae muchas opiniones favorables. Sin embargo, la única oportunidad en la que este tema fue oficial y seriamente debatido fue en ocasión de la reforma en la comisión de Constitución del Congreso, y una vez escuchadas las diferentes opiniones, la opción que prevaleció fue la de mantener dicha separación, teniendo en mente, probablemente, la actuación de tales organismos en los años inmediatamente anteriores.

De otro lado, no debiera resultar extraño que en la percepción ciudadana, la mayoría de las personas pueda estar más de acuerdo con la propuesta de unificar los organismos electorales que con la de mantenerlos separados. Así, por ejemplo, en una encuesta aplicada por la Asociación Civil Transparencia en el 2001, a la pregunta «¿Usted cree que deben juntarse el JNE, la ONPE y el RENIEC en una sola institución?», una clara mayoría se pronunció a favor de la unificación de los órganos electorales, como se ve en el cuadro 4.

Cuadro 4. Encuesta de la Asociación Civil Transparencia, febrero de 2002: «¿Usted cree que deben juntarse el JNE, la ONPE y el RENIEC en una sola institución?"

\begin{tabular}{|c|c|c|c|c|c|c|c|c|c|c|c|}
\hline & \multirow[t]{2}{*}{ General } & \multicolumn{2}{|c|}{ Sexo } & \multicolumn{4}{|c|}{ Edad } & \multicolumn{4}{|c|}{ Instrucción } \\
\hline & & Hom & Muj. & $0-25$ & $26-35$ & $36-45$ & 46-más & Ning. & Prim. & Sec. & Sup \\
\hline Sí & 46 & 48 & 42 & 41 & 45 & 48 & 49 & 22 & 41 & 49 & 56 \\
\hline No & 30 & 30 & 31 & 34 & 33 & 28 & 26 & 34 & 28 & 33 & 33 \\
\hline No sabe & 24 & 21 & 27 & 25 & 21 & 24 & 25 & 58 & 31 & 18 & 10 \\
\hline$N$ & (3126) & (1905) & (1221) & (698) & (928) & (771) & (729) & (165) & (1187) & (1159) & $(615)$ \\
\hline
\end{tabular}

Fuente: opinión de Transparencia sobre el proyecto de reforma del sistema electoral del Jurado Nacional de Elecciones, Lima, 14 de febrero del 2002 (http://transparencia.org.pe/web/pronunciamientos/opinion.rtf) 
$\mathrm{Al}$ presentar el resultado de esta encuesta, Transparencia hace la observación de que cuanto mayor es el nivel de educación, mayor es también el porcentaje de encuestados que se manifiestan a favor de tal unificación.

A pesar de tales resultados, hay que reparar en el alto porcentaje de personas que prefirió mantener la separación $(30 \%)$ y en el todavía más alto porcentaje que no se pronunció al respecto (24\%). En consecuencia, teniendo presente que para el año 2001 la experiencia era todavía muy reciente y es probable que estuviera aún muy presente en los electores la tradición de contar solo con un órgano electoral — que se remonta a principios de la década de 1930-, solamente un porcentaje inferior a la mitad de los encuestados se llegó a expresar en favor del regreso al modelo anterior.

Al mismo tiempo, la insistencia de los miembros del JNE no ha ido acompañada de mayores argumentos que aquellos que aluden a la tradición, la unidad de conducción o la supuesta economía de recursos que podría derivar de una decisión favorable a la unificación.

En tal sentido, al margen de tales argumentos promovidos por quienes al interior del JNE están más próximos a la experiencia judicial — que parecieran responder en buena medida a la manera en que equivocadamente se ha entendido la organización jurisdiccional como una estructura jerárquica—, interesa advertir la manera como han sido llevados a cabo los procesos y consultas electorales a partir de abril del año 2001 y, en función a ello, evaluar cuál podría resultar la opción más idónea a futuro.

En esa perspectiva, cabe afirmar que tal evaluación arroja elementos de juicio mucho más favorables, si bien no necesariamente en favor del mantenimiento de tres —o cuando menos dos- órganos separados, definitivamente a favor de mantener a la ONPE como un organismo constitucional autónomo a cargo de la organización de los procesos electorales y asumiendo todas las funciones administrativas necesarias al efecto.

Así, aceptando de un lado la opinión que ha ido ganando consenso respecto a la conveniencia de separar al RENIEC del denominado sistema electoral, de otro lado puede apreciarse que el grado de legitimidad, aceptación de resultados y respaldo que en general han podido alcanzar los organismos electorales, se debe más a una organización de los procesos bajo criterios técnicos y de eficiencia mostrada por la ONPE en cada oportunidad que a las intervenciones del JNE. En efecto, desde el seguimiento realizado por la Defensoría del Pueblo de los sucesivos procesos electorales habidos desde abril del 2001, así como de situaciones que merecieron un pronunciamiento del JNE, se pudo apreciar una actuación que con frecuencia resultó contradictoria, equivocada o poco permeable a las exigencias de una realidad social que demandaba pronunciamientos creativos, capaces de garantizar la plena realización de los derechos fundamentales. Antes bien, se pudo advertir en tales circunstancias la 
aplicación mecánica de criterios rígidos por parte del JNE, que terminaban desvirtuando tales derechos e imponiendo decisiones que en la práctica resultaban contraproducentes para el debido procesamiento de los conflictos en materia electoral.

De esa manera, independientemente de la recurrencia con la que el JNE intentó poner en cuestión la competencia de la Defensoría del Pueblo (DP) para supervisar los procesos electorales o para intervenir en materia electoral - lo que de suyo mostró una escasa disposición para admitir un funcionamiento del aparato estatal bajo una lógica de complementariedad en favor de la ciudadanía-, han sido frecuentes las oportunidades en las que el indicado órgano electoral ha respondido negativamente a las recomendaciones defensoriales, sin argumentos de sustento atendibles, a pesar de la gravedad de los problemas sociales generados en diversas localidades, que demandaban un pronunciamiento del JNE como medio de canalizar su adecuado procesamiento, objetivo al que precisamente intentaba contribuir la DP.

Los sucesivos informes defensoriales haciendo conocer los resultados de la supervisión realizada a los diferentes procesos electorales que tuvieron lugar desde fines de la década pasada, dan cuenta pormenorizada de tales respuestas negativas. A modo de ilustración, sin embargo, conviene hacer aquí expresa referencia a cuatro casos o situaciones que permiten apreciar la pertinencia de lo expuesto respecto a la actuación del JNE. No cabe duda que en algunos de ellos hubo elementos de naturaleza compleja y que una revisión detenida de las eventuales responsabilidades terminaría por señalar a diferentes actores e instancias, pero no es un análisis de estos aspectos lo que se pretende realizar aquí. Interesa en este sentido llamar la atención únicamente sobre algunos aspectos que resultan relevantes desde la perspectiva de evaluar la actuación que le cupo realizar al JNE en tales circunstancias.

\section{a) El conflicto en Ilave}

El agudo conflicto que se desató en esta provincia de Puno — donde tuvo lugar el linchamiento del entonces alcalde provincial de Ilave en Puno, Cirilo Fernando Robles Callomamani-generó un serio problema respecto a la recomposición del concejo municipal en ese lugar, toda vez que no solo se trataba de la vacancia en el cargo de la alcaldía por el fallecimiento del titular, sino de la situación de los otros nueve regidores que, habían renunciado, habían sido detenidos por su presunta participación en el asesinato del alcalde, o se encontraban con orden de captura por el mismo motivo. En esas circunstancias, el JNE publicó, con fecha 24 de mayo de 2004, la resolución 098-2004-JNE, a través de la cual este organismo llamó a suceder en los cargos de regidores, a 
personas de listas diferentes a las que habían ganado las elecciones en ese lugar en octubre del año 2003. Asimismo, el JNE solicitó en dicha resolución que el presidente de la República procediera a convocar a elecciones parciales a fin de cubrir únicamente cuatro vacantes.

A juicio de la DP, sin embargo, la grave situación producida en Ilave había provocado la ruptura de la proporcionalidad en la representación en el concejo provincial de esa provincia, generándose además la imposibilidad material de mantener la línea sucesoria en los cargos, sin vulnerar el mandato constitucional que exige mantener la representación proporcional. En esas condiciones, la única manera de recomponer la autoridad municipal era la convocatoria a elecciones para cubrir la totalidad de las nueve plazas de regidores así como la del alcalde provincial.

Las recomendaciones de la DP no fueron atendidas, con lo que las decisiones adoptadas por el JNE variaron unilateralmente la composición de mayorías y minorías, instalando en el cargo de regidores, además, para que completaran el período, a cinco personas que pertenecían a listas perdedoras en las elecciones de noviembre del año 2002. De esa manera, el JNE vulneró el artículo 187 de la Constitución y, al declarar directamente las vacancias y suspensiones en el concejo provincial, asumió atribuciones que no le estaban legalmente establecidas.

Huelga señalar los riesgos derivados de decisiones como las adoptadas en este caso, en un medio socialmente convulsionado y en el que, adicionalmente, a pesar de haber convocado a elecciones para cubrir únicamente cinco plazas, se permitió que las listas que postularon lo hicieran con nueve candidatos(as) cada una.

\section{b) El conflicto en Suyo}

Las elecciones de noviembre de 2002 en este distrito piurano dieron lugar a una denuncia de fraude por parte del grupo que había obtenido la segunda mayor votación. Alegaba que el fraude se había producido por suplantación de las actas electorales correspondientes a la Oficina Descentralizada de Procesos Electorales (ODPE) y el Jurado Electoral Especial (JEE) de Ayabaca. Cabe agregar que desde el mismo día de las elecciones se había hecho pública la diferencia entre los resultados de la ODPE y los de la ONPE, dado que en la página web de esta última aparecieron los resultados mesa por mesa de ese distrito, y en ellos constaba que el ganador había sido quien aparecía en el segundo lugar según el acta de la ODPE y el JEE.

No obstante tales constataciones, las actas mostradas por los personeros y las testimoniales brindadas, el JNE optó por convalidar los resultados iniciales. Poco después se abrió un proceso penal contra los implicados en el presunto 
fraude, que concluyó con sentencia condenatoria definitiva en los primeros meses del año 2004. De esta manera quedó acreditada la suplantación de actas y la comisión de delito contra la fe pública.

Como era de esperar, un significativo número de pobladores de Suyo se movilizó entonces pidiendo la nulidad de los resultados electorales y el correspondiente cese del alcalde. El JNE se pronunció señalando que el tema ya había sido «resuelto en forma definitiva». Esta respuesta provocó una protesta que fue en aumento y que, entre otras manifestaciones, incluyó plantones y vigilias en la plaza de armas de Suyo. Hacia el 16 de junio la protesta se tornó violenta, resultando dos personas detenidas y doce heridas, siete de las cuales pertenecían a la Policía Nacional.

Antes de que se produjeran los hechos violentos, la DP ya se había dirigido al JNE recomendándole considerar la situación extraordinaria que se había producido en ese distrito a propósito de la sentencia de penal condenatoria e instándolo a que atendiera la demanda que en ese momento era respaldada por prácticamente toda la población del lugar. Este pedido se sostenía en que, en los hechos, quien ostentaba el cargo de alcalde provincial no era la persona que había sido elegida, lo que contradecía el mandato constitucional de que "[...] el sistema electoral tiene por finalidad asegurar que las votaciones traduzcan la expresión auténtica, libre y espontánea de los ciudadanos; y que los escrutinios sean reflejo exacto y oportuno de la voluntad del elector, expresada en las urnas por votación directa» (artículo 176 de la Constitución).

Entre tanto, se había hecho también público que tanto el acta del JNE como el de las Fuerzas Armadas coincidían con el de la ONPE, confirmando que el real ganador era el otro candidato. Nuevamente, sin embargo, el JNE respondió que la decisión sobre este tema tenía carácter definitivo y que no podía ser materia de revisión.

No con poca dificultad, este conflicto pudo ser más tarde canalizado a través de una consulta para revocatoria; pero el desenlace pudo ser distinto y haber dado lugar a hechos todavía más graves que los que tuvieron lugar, a partir de una decisión del JNE que ciertamente contrariaba la voluntad y los derechos fundamentales de los ciudadanos.

\section{c) El cálculo de votos en las consultas para revocatoria}

Los primeros procesos de consulta para revocatoria tuvieron lugar en 1997, arrojando como resultado 42 alcaldes $(68.85 \%$ del total consultado) y 93 regidores $(72.09 \%$ del total de las consultas) revocados. De esa manera, se hizo evidente la bondad de estos procedimientos para permitir un canal pacífico y legal para canalizar situaciones de conflicto en diversas localidades del país. 
Posteriormente, sin embargo, el JNE decidió cambiar la interpretación de la norma (artículo 23 de la Ley de Participación y Control Ciudadanos) que en las consultas anteriores había permitido considerar en el cálculo - para definir la mayoría exigida para revocar (52\%) — únicamente al total de los electores efectivos, optando por considerar ahora al total de los electores según el padrón electoral.

Este cambio de criterio determinó que en las consultas realizadas en 1999, no obstante que se presentó un mayor número de solicitudes que en 1997, solo llegaron a ser revocados 11 alcaldes (6.62\% de los que entraron a la consulta) y 27 regidores (5.84\% de los consultados). En la práctica, de esta manera se afectó seriamente la posibilidad de encontrar en este mecanismo de consulta un medio idóneo de canalización de conflictos, así como la confianza ciudadana en el mismo.

En repetidas oportunidades la DP se dirigió infructuosamente al JNE solicitándole reconsiderar este criterio, señalándole, entre otros argumentos, que en el Perú es muy frecuente que el padrón electoral se encuentre sobredimensionado por la migración o movilidad interna, lo que resultaba particularmente grave en el caso de los municipios rurales.

La supervisión realizada por la DP desde el año 2004 en torno a múltiples conflictos surgidos en diferente lugares del territorio nacional, y cuyos reportes permitían apreciar que más del $70 \%$ de los mismos se generaban en zonas rurales y confrontaban a la población con sus autoridades municipales, hizo que esta institución insistiera - esta vez ante el Congreso de la República - en la necesidad de variar la interpretación adoptada por el JNE.

Finalmente, en diciembre del 2004, el Congreso aprobó la ley 28421, en la que se estableció que en las consultas por revocatoria, únicamente se tomarían en cuenta a los electores efectivos. Una vez más, la poca permeabilidad del JNE para interpretar la ley conforme al interés ciudadano y a lo establecido en la propia Constitución fue un elemento que contribuyó significativamente a agudizar los conflictos y a provocar una mayor desconfianza en la población respecto a la efectividad de los mecanismos institucionales de solución de controversias.

\section{d) Las «cuotas» electorales}

Para las elecciones generales del año 2001, la Ley Orgánica de Elecciones había establecido que la cuota electoral para las listas que postulaban al Congreso de la República quedaba fijada en $30 \% .{ }^{15}$

15 Ello conforme a la ley 27387 publicada el 15 de noviembre de 2000, una norma que modificó varios artículos de la ley electoral y que varió el porcentaje de la cuota anteriormente previsto en un $25 \%$. 
Mediante la resolución 068-2001-2001-JNE, publicada el 24 de enero del mismo año, ese organismo aprobó un cuadro en el que señalaba el número de candidatos o candidatas que, como mínimo, debían integrar cada lista en los 25 distritos electorales para cumplir con la cuota legal del 30\%.

La Defensoría del Pueblo se dirigió entonces al JNE comunicándole su preocupación, toda vez que del cuadro publicado podía advertirse fácilmente que en los casos de tres distritos electorales (Ica, Callao y La Libertad), el número fijado representaba menos del $30 \%$, por lo que en esos casos no se estaba cumpliendo con la ley y en definitiva reducía a 44 el número mínimo de candidatas en vez de las 47 que hubieran correspondido de aplicarse el 30\% también en esos lugares.

De la revisión de los datos publicados, resultaba obvio que al calcular la cuota y obtener un entero con fracción, el JNE había procedido a redondear al entero inferior, obteniendo así un número cuyo porcentaje resultaba inferior al $30 \%$, olvidando que la ley exigía esa cuota como mínimo. No obstante las diferentes comunicaciones cursadas con anterioridad al vencimiento del plazo para la inscripción de listas y la contundencia de la argumentación expuesta —que por lo demás reposaba en un simple cálculo matemático-, el JNE se negó a rectificar su resolución y declaró más bien improcedentes los pedidos que se habían formulado en ese sentido. Al mismo tiempo, voceros del JNE recordaron que esta entidad constituye la última instancia en materia electoral, siendo sus resoluciones inapelables. ${ }^{16}$

Producido el rechazo del JNE para atender una demanda absolutamente legítima y de evidente sustento, la DP, con la finalidad de impedir que de esta manera se estableciera tan negativo precedente, decidió presentar una petición ante la Comisión Interamericana de Derechos Humanos por el incumplimiento de la cuota en los tres distritos electorales indicados. La petición fue formulada en agosto del año 2001, conjuntamente con el Movimiento Manuela Ramos, sobre la base de señalar que se había vulnerado el derecho a la igualdad y no discriminación, el derecho a la participación política, así como el deber de respeto y garantía de los derechos conforme lo establece la Convención.

En la actualidad, el proceso seguido ante la Comisión Interamericana se encuentra en una etapa de negociación para un acuerdo amistoso que se espera concluya satisfactoriamente, garantizando que a futuro no se repita un equívoco

16 La Comisión Interamericana de Derechos Humanos, mediante el informe n. ${ }^{0}$ 119/99 de octubre de 1999 (caso 11.428), ha señalado que las disposiciones del ordenamiento jurídico peruano que establecen que las resoluciones del JNE «son dictadas en instancia final, definitiva y no son revisables. Contra ellas no procede recurso alguno", violan el derecho a un recurso sencillo y rápido, tal como lo prevé el artículo 25 de la Convención Americana de Derechos Humanos. 
de esta naturaleza. De esta manera se podrá evitar que se termine perjudicando en los hechos la participación política de las mujeres, a partir de una falta de comprensión del sentido y los alcances de las acciones afirmativas, y de una nula disposición por parte del JNE para rectificar errores ostensiblemente identificados.

\section{e) La necesidad de revisar el diseño}

Lo expuesto en los casos precedentes constituye parte de una tendencia que ha sido lamentablemente constante en el JNE y que pone en evidencia una ejecutoria institucional ajena, o cuando menos distante, de las exigencias que una compleja realidad como la peruana plantean al desarrollo de un sólido proyecto democrático. Buena parte de las deficiencias señaladas en el Poder Judicial, y en la magistratura en particular, se han visto trasladadas así al ámbito del JNE. Tales deficiencias se relacionan con un manejo excesivamente formalista o rígido, apegado al sentido literal de la norma, y que contraría muchas veces los derechos constitucionalmente protegidos. El JNE ha mostrado un comportamiento similar, probablemente a partir de su propia composición, muy próxima al ámbito jurisdiccional.

De otro lado, ha sido también una constante el pedido de diferentes instancias de que se precisen mejor las competencias y atribuciones que corresponden a cada organismo electoral, toda vez que con frecuencia se han presentado interferencias o superposiciones que afectan la marcha regular de los procesos electorales y que generan costos innecesarios, no obstante la conocida escasez de recursos.

Esta situación no solamente ha generado problemas para la coordinación necesaria entre las tres instituciones, sino que ha provocado que el Tribunal Constitucional deba intervenir para resolver algunos conflictos de competencia. Ciertamente, es poco probable que estos mismos problemas hubieran tenido lugar si en el propio diseño constitucional y en la legislación posterior se hubiera optado por separar nítidamente las funciones administrativas de las jurisdiccionales en materia electoral.

Así, competencias tales como el mantenimiento y custodia del registro de organizaciones políticas, o la determinación de circunscripciones territoriales y la sede de las mismas, que actualmente corresponden al JNE — según lo contemplan la Constitución y la Ley Orgánica de Elecciones, respectivamente-, son propias de un ámbito administrativo y no debieran ser asumidas por la entidad que tiene la función de resolver las controversias que precisamente puedan generarse a partir de las decisiones administrativas.

En definitiva, todo indica que lo más aconsejable es revisar el modelo institucional tripartito que consagra la actual Constitución, teniendo muy 
presente sobre todo la experiencia de los últimos seis años, así como los avances tecnológicos que han permitido hacer más eficiente, confiable y ágil la organización de los procesos electorales.

De esa manera, atendiendo a la indicada experiencia y a criterios de especialización, las funciones electorales de naturaleza administrativa, tales como la planificación, organización y ejecución de los procesos electorales, debieran estar en manos de la entidad a cargo de la organización de los procesos, derivando el conocimiento de los diferendos que de allí puedan suscitarse a las instancias jurisdiccionales.

Una alternativa en esa dirección, partiendo de reconocer que existe un creciente consenso para excluir al RENIEC del ámbito electoral, sería la de mantener a la ONPE como un órgano constitucional autónomo con competencia en todas las funciones electorales de carácter administrativo, fortaleciendo su organización a través de una estructura que cubra de manera permanente todo el territorio nacional.

Las funciones de naturaleza jurisdiccional podrían a la vez ser asumidas, ya sea por un tribunal o corte electoral a constituir en cada oportunidad en la que se convoca a un proceso de elecciones generales, ya sea por el Poder Judicial ordinario o el Tribunal Constitucional, en los que se establecerían salas especializadas al efecto.

\subsection{Los partidos políticos y su nuevo marco normativo}

\section{a) La Constitución y el rol de los partidos políticos}

Es evidente que la opción de la Constitución de 1993 fue la de rebajar el rol de los partidos políticos al mínimo, como puede apreciarse nítidamente en el tenor del artículo 35 de la Carta. Así, se parte de entender la participación política ciudadana como un derecho que puede, por igual, ser ejercido de manera individual o «[...] a través de organizaciones políticas como partidos, movimientos o alianzas, conforme a ley [...]». Se asemeja entonces la calidad de partido político a la de cualquier otra organización que persigue fines de esa naturaleza, tales como movimientos o alianzas electorales, reconociendo que todas ellas concurren por igual a la formación y manifestación de la voluntad popular.

Esta relativización de los partidos políticos, si bien se entronca con la opción tradicionalmente adoptada en nuestros textos constitucionales hasta 1933 - en los que el tema de la ciudadanía se aborda esencialmente en torno al derecho del sufragio, omitiendo toda mención a los partidos políticossin embargo con la Constitución de 1979, cuyo texto asignó expresamente a estos partidos, en su artículo 68, un rol fundamental para la participación 
ciudadana, señalando además que ellos «[...] expresan el pluralismo democrático. Concurren a la formación de la manifestación de la voluntad popular».

Aquella Constitución, por tanto, que puso fin a once años de gobierno de facto e inauguró una nueva etapa en la política nacional, fue expresa en destacar la importancia de los partidos políticos y orientó, en consecuencia, su contenido a promover la participación de la ciudadanía en la política, a través de ese tipo de organizaciones. De plano, el ejercicio del derecho de sufragio se vinculó en el texto de esa Constitución a la competencia que debían desarrollar entre sí los partidos políticos, concediéndoles al efecto derechos específicos, particularmente durante las campañas electorales.

Por cierto, la Constitución de 1979 no negaba el derecho de los ciudadanos a participar en la vida política al margen de los partidos políticos, de manera independiente, pero ello aparecía como una modalidad marginal que, en todo caso, debía ser prevista y regulada por ley.

Ahora bien, acorde con su estilo y mensaje, y en clara sintonía con el contexto político que le permitió llegar al poder en las elecciones generales de 1995, el presidente Fujimori desarrolló desde los inicios de su gobierno una campaña permanente de desprestigio y satanización de los partidos políticos, responsabilizándolos de todos los graves problemas por los que atravesaba el país, principalmente económicos y de seguridad ciudadana.

Esa imagen de los partidos, que coincidía en buena medida con la de un sector muy significativo de la ciudadanía, se reafirmó a partir de abril de 1992 cuando se produjo la ruptura constitucional que marcó el inicio del ejercicio autoritario del poder que caracterizó al régimen desde ese entonces.

La Constitución de 1993, en cuya elaboración tuvo un rol determinante la mayoría oficialista que representaba al régimen en el CCD, no hizo sino expresar esa concepción, formalizando, en el más alto nivel normativo, las condiciones para incidir en un mayor debilitamiento de las organizaciones partidarias desconociéndoles en lo sustantivo la identidad que les confería la Constitución anterior que calificaba a estas organizaciones como instrumentos fundamentales de la participación política ciudadana. Por el contrario, se buscó promover el ejercicio individual e independiente de la participación política, a través de organizaciones frágiles y muchas veces episódicas, a las que se les otorgó un tratamiento análogo al de los partidos.

Esta misma voluntad de propiciar un mayor debilitamiento de las organizaciones partidarias se reitera en el actual texto constitucional, al ser estas - y no los movimientos o alianzas - las que debían cumplir, de acuerdo a ley, con establecer mecanismos democráticos para su funcionamiento orgánico y la transparencia en el origen de sus recursos económicos.

De esa manera, no obstante la conveniencia de establecer tales exigencias a los partidos políticos, es evidente que al no haber sido planteadas también 
para las otras formas de organización, se buscó estimular la elección de estas últimas como modalidades más simples y expeditivas de participar en los procesos electorales. Ello teniendo presente que en el país no existe una práctica de transparencia en el manejo de los recursos partidarios ni una tradición democrática al interior de los mismos. En este sentido, cabe reconocer que los propios partidos políticos se habían mostrado reacios a la aprobación de una ley que los regulara, presumiblemente por cuanto se quiso evitar una discusión que, a todas luces, los obligaría a abordar ambos aspectos.

En efecto, desde 1980, cuando se reestableció en el país el régimen constitucional, los sucesivos Congresos discutieron infructuosamente en repetidas oportunidades la aprobación de una ley de partidos políticos. No obstante el aparente consenso alcanzado para ese propósito, las diferentes iniciativas quedaron sin culminar una y otra vez, al punto de generar la impresión de que existía una voluntad mayoritaria no explícita de evitar la dación de una norma de esta naturaleza.

Diversos factores incidieron en que se frustrara tantas veces el propósito de contar con una ley de partidos, pero un atento seguimiento de los proyectos y debates sobre el tema corrobora lo expuesto acerca de las resistencias a establecer con precisión los mecanismos de democracia interna en cada organización, así como los necesarios para transparentar el manejo de recursos y el financiamiento de los partidos, particularmente durante los períodos de campaña electoral.

Todo ello contribuyó a la debilidad formal y real de los partidos políticos, y esta situación no ha podido ser revertida, no obstante la dimensión y profundidad de los cambios producidos hacia fines del año 2000, cuando se produjo la caída del régimen de Fujimori. Así, al asumir la presidencia del gobierno don Valentín Paniagua, se inició un período de transición orientado a recuperar la institucionalidad y generar las condiciones para la realización de nuevas elecciones generales, que otorgaran plena legitimidad a quienes accedieran al nuevo gobierno y Parlamento nacional. Se esperaba, así, sentar las bases para el desarrollo de un sólido proyecto democrático en el país.

En este nuevo contexto, fue una constante en el discurso político de los diferentes actores, señalar la importancia y gravitación de los partidos políticos para el desarrollo de la democracia. Más allá de las críticas — acompañadas de algunas autocríticas - respecto al comportamiento y rol jugado por los partidos políticos hasta ese entonces, se puede afirmar que se construyó un consenso básico acerca de la necesidad de fortalecerlos y apostar a una nueva relación con la ciudadanía, buscando superar la crisis de representatividad que ya para ese momento resultaba manifiesta. 


\section{b) Y al fin, una ley de partidos políticos}

Instalado el nuevo Congreso en julio de 2001, anunció que la ley de partidos políticos formaría parte de su agenda prioritaria. No obstante ello, no fue sino hasta octubre del año 2003 que se promulgó la ley 28094, que se convirtió en la primera ley de partidos políticos de la historia del Perú.

Para la fecha de promulgación de la norma ya se contaban en más de treinta los proyectos que se habían presentado en el Congreso de la República y que se venían discutiendo en la Comisión de Constitución sobre ese tema. Fue muy importante para la aprobación de esta norma, el esfuerzo realizado por la Asociación Civil Transparencia y por Internacional IDEA, desde febrero del año 2002, para tratar de crear consenso en torno a un solo proyecto que sistematizara los existentes. Estas organizaciones convocaron a una mesa de partidos políticos en la que participaron representantes de doce fuerzas políticas del país, y fue sobre la base del proyecto allí consensuado, que el Pleno del Congreso aprobó finalmente la ley.

No puede soslayarse, sin embargo, que en el proceso de discusión del proyecto en el Congreso, los temas relacionados con la democratización y transparencia financiera fueron los que generaron mayor tensión, dando lugar incluso a la presentación de textos que sustituían a los aprobados originalmente en la Comisión de Constitución, que desvirtuaban en buena medida los alcances que se pretendían obtener en estos aspectos con arreglo al proyecto original. ${ }^{17}$

De cualquier manera, el contraste entre el proyecto que ingresó al debate para su aprobación final y el aprobado en el Pleno, permite apreciar algunas modificaciones preocupantes en la línea de lo anteriormente expuesto. Así, cuestiones como reemplazar el inciso c del artículo 25 de la ley para que sean los «órganos partidarios conforme al estatuto» y no los «delegados elegidos por voto universal» — como lo disponía el proyecto- los que decidieran la nominación de los candidatos al Ejecutivo, Congreso, gobiernos regionales y municipales, sustentan esa preocupación.

Asimismo, en lo que toca al manejo de recursos, el haber suprimido las disposiciones sobre el límite de los gastos en campaña (artículo 34 del proyecto), o las relativas al impedimento para recibir donaciones anónimas (artículo 31) así como las de rendición de cuentas, con ingreso de la información a la Contraloría General de la República (artículo 37), ponen en evidencia que las resistencias para transparentar estos movimientos financieros están todavía muy presentes.

7 Con fecha 29 de septiembre, la Asociación Civil Transparencia e Internacional IDEA enviaron una carta a los principales líderes parlamentarios en la que señalaban diecisiete puntos introducidos en el nuevo dictamen que terminaban afectando precisamente los aspectos relativos a la democratización y el manejo transparente de recursos en los partidos. 
De otro lado, al margen de la tarea pendiente de revisar el actual texto constitucional con relación a los partidos políticos, toda vez que este no guarda correspondencia con los contenidos esenciales de la ley aprobada, se hace necesario también ampliar la discusión respecto de algunos aspectos de este cuerpo normativo que deben también ser ajustados. Tales ajustes habría que plantearlos en función de las deficiencias que han sido señaladas alrededor de los temas comentados, o aquellas que han sido identificadas a la luz de la experiencia, en lo que toca a los mecanismos de verificación o sanción que los organismos electorales no parecen haber podido aplicar eficazmente.

Si no se garantiza el funcionamiento de mecanismos eficaces de democratización interna en los partidos políticos, difícilmente se darán las condiciones para que un número significativo de ciudadanos pueda interesarse en participar en la política a través de las organizaciones partidarias.

En tanto esta siga siendo la constante, es evidente que los peruanos estaremos librados en buena medida a la improvisación y el surgimiento de caudillos o candidaturas mesiánicas, con gran posibilidad de trastocar - aun de manera episódica - el proceso político en el país. Al mismo tiempo, si no se adoptan medidas más audaces para superar la debilidad endémica de los partidos, esta puede terminar ahondándose, toda vez que frente al manejo de cúpulas articuladas en torno a un líder indiscutible, los militantes más calificados, los más apegados a un ejercicio crítico y libre de su vida política, tienden a separarse o quedar aislados. De esa manera, la organización puede fácilmente caer en manos de una mayoría poco dispuesta a participar en debates o ejercicios racionales de orden ideológico o programático, y más interesada en algún tipo de beneficio u oportunidad de obtenerlo como contrapartida a su lealtad. 